\title{
BMJ Open Good practice or positive action? Using $Q$ methodology to identify competing views on improving gender equality in academic medicine
}

\author{
Louise D Bryant, ${ }^{1}$ Paula Burkinshaw, ${ }^{2}$ Allan O House, ${ }^{1}$ Robert M West, ${ }^{1}$ \\ Vicky Ward ${ }^{1}$
}

To cite: Bryant LD,

Burkinshaw P, House A0, et al. Good practice or positive action? Using $Q$ methodology to identify competing views on improving gender equality in academic medicine. BMJ Open 2017;7:e015973. doi:10.1136/ bmjopen-2017-015973

- Prepublication history for this paper is available online. To view these files please visit the journal online (http://dx.doi org/10.1136/bmjopen-2017015973).

Received 16 January 2017 Revised 22 May 2017 Accepted 2 June 2017

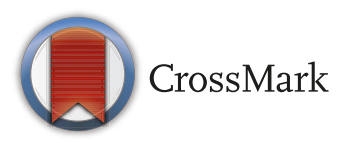

${ }^{1}$ Leeds Institute of Health Sciences, University of Leeds, Leeds, UK

${ }^{2}$ Leeds University Business School, University of Leeds, Leeds, UK

Correspondence to Dr Louise D Bryant; I.d.bryant@leeds.ac.uk

\section{ABSTRACT}

Objectives The number of women entering medicine has increased significantly, yet women are still underrepresented at senior levels in academic medicine. To support the gender equality action plan at one School of Medicine, this study sought to (1) identify the range of viewpoints held by staff on how to address gender inequality and (2) identify attitudinal barriers to change. Design $Q$ methodology. 50 potential interventions representing good practice or positive action, and addressing cultural, organisational and individual barriers to gender equality, were ranked by participants according to their perception of priority.

Setting The School of Medicine at the University of Leeds, UK.

Participants Fifty-five staff members were purposively sampled to represent gender and academic pay grade.

Results Principal components analysis identified six competing viewpoints on how to address gender inequality. Four viewpoints favoured positive action interventions: (1) support careers of women with childcare commitments, (2) support progression of women into leadership roles rather than focus on women with children, (3) support careers of all women rather than just those aiming for leadership, and (4) drive change via high-level financial and strategic initiatives. Two viewpoints favoured good practice with no specific focus on women by (5) recognising merit irrespective of gender and (6) improving existing career development practice. No viewpoint was strongly associated with gender, pay grade or role; however, latent class analysis identified that female staff were more likely than male to prioritise the setting of equality targets. Attitudinal barriers to the setting of targets and other positive action initiatives were identified, and it was clear that not all staff supported positive action approaches.

Conclusions The findings and the approach have utility for those involved in gender equality work in other medical and academic institutions. However, the impact of such initiatives needs to be evaluated in the longer term.

\section{INTRODUCTION}

Women remain under-represented at senior levels in virtually all levels of academic medicine. ${ }^{12}$ For example, fewer than $20 \%$ of clinical

\section{Strengths and limitations of this study}

- The first ever study to apply Q methodology to the area of gender inequality in medical schools.

- $Q$ methodology is an ideal approach to evidencing the range of views on gender inequality in the academic workplace, which are already known to be multiple and contested.

- The inclusion of latent class analysis provided some further insight into where key differences about gender equality initiatives lie.

- The research was limited to one (large) medical school and additional viewpoints may exist in other institutions.

- As a qualitative approach Q methodology describes the nature and landscape of viewpoints rather than their prevalence in the population.

academic professors in the UK are female, compared with $41 \%$ of clinical lecturers, ${ }^{3}$ evidence of what has been called the "leaky pipeline'. Women also tend to progress through pay grades more slowly than men and are paid less than men overall. ${ }^{5}$ There are significant female attrition rates in particular specialisms such as academic surgery. ${ }^{6}$ It is likely that many women's career choices in medicine and medical research reflect constraints attributable to an accumulation of gendered disadvantage, both perceived and actual. ${ }^{78}$

Few women in academic medicine report overt gender discrimination, but more women than men perceive inequities in promotion, salary, access to resources and fellowship opportunities. ${ }^{7}$ Women are less likely to report a sense of belonging in medical academia and are less confident about their career advancement than men. ${ }^{9}$ Although some argue that female academic clinicians make an active choice to prioritise family over career, women report being as eager as men to assume leadership positions. ${ }^{910}$ 
This waste of female academic talent is widely acknowledged as a concern. ${ }^{11} 12$ The Athena Scientific Women's Academic Network (SWAN) initiative was launched in the UK in 2005 to advance the careers of women in STEMM (science, technology, engineering, maths and medicine) higher education and research. This initiative has gained momentum in UK medical schools since achievement of Silver chartered status ('a significant record of activity and achievement by the institution in promoting gender equality ${ }^{13}$ ) became a prerequisite for government funding for biomedical research centres. ${ }^{14}$

This study was undertaken in 2014 as part of an Athena SWAN strategy in one UK medical school. The aim of the study was to provide evidence to inform the development and implementation of an action plan to address gender equality challenges in the school. This study had two objectives: (1) identify the range of viewpoints held by academics on how to address gender inequality and (2) identify attitudinal barriers to implementing these interventions.

\section{METHODS}

\section{Materials and methods}

$\mathrm{Q}$ methodology aims to detect the range of subjective viewpoints on a topic within a given population by requiring participants to consider and respond to a set of predefined statements on the topic under investigation. It is a sensitive method for exploring tension between socially acceptable views and personal beliefs and values, making it an ideal approach to explore views on gender equality initiatives and positive action in the workplace, initiatives that are known to be debated and contested. ${ }^{15}$ The method combines qualitative approaches to sampling and pattern interpretation with quantitative research techniques and analyses. ${ }^{16}$

$Q$ methodology starts from the assumption that for each social topic there is a 'flow of communicability' called the concourse. ${ }^{17}$ The concourse consists of the things that are written or said about a topic that can be 'socially contested, argued about and debated... matters of values and beliefs'. ${ }^{8}$ The method requires participants to consider and respond to a set of predefined statements sampled from the concourse (called the $Q$ set) using a ranking technique called $Q$ sorting. The method is concerned with the relationships between individuals' views as expressed in their $Q$ sorts and so uses factor analytic techniques to identify how viewpoints cluster together. ${ }^{19}$ The techniques invert the usual factor analytic approach by using participants as the variables central to the factoring process rather than the items in the $Q$ set. The pattern of statement placement for each factor is interpreted qualitatively, and a narrative is created that represents a distinct point of view on the topic under study.

\section{Developing the $\mathbf{Q}$ set}

For this study the concourse was defined as interventions that had already been tried or suggested as ways to address gender inequality in academic medicine and related STEM disciplines. Candidate interventions were identified from a review of the academic and grey literature on gender equality interventions in the workplace, which was not confined to the UK. From this review 154 candidate interventions were initially identified. These interventions were thematically analysed by type of intervention, for example 'mentoring' and 'flexible working', and organised using a framework that categorised interventions along two dimensions that had emerged from a detailed reading of the concourse materials. The first dimension was intervention target (good practice or positive action): the target of good practice interventions was all staff members (equal treatment), whereas the target of positive action interventions was specifically women. ${ }^{20}$ The second dimension was intervention level (individual, organisational or cultural), which was informed by other multilevel approaches to change implementation ${ }^{21}{ }^{22}$ (see table 1 for examples of interventions categorised using the framework). During a series of research meetings, the original 154 interventions were refined and reduced down to the final 50 (see figure 1). For example, where three different interventions about training in unconscious bias had been identified, one item was selected to represent this type of intervention.

\section{Participant sample}

We anticipated that respondents' opinions would be influenced by experience in their current academic department, by gender and by pay grade, and therefore sampled academic staff members strategically across these variables. Key members of the school's Athena SWAN teams were asked to identify members of staff in their institutes across gender, pay grade and potential diversity of viewpoint. In addition, members of the School Executive were invited to take part to enable representation of views at senior decision-making levels. Only two staff of those invited declined to participate; both were male. Fifty-five members of staff participated (31 women, 24 men) (see table 2). Ages ranged between 27 and 63 years (mean 45 years). The sample met the two main sufficiency criteria of $Q$ methodology: first that the sample provides sufficient diversity of viewpoint across the variables of interest, and second that there are enough participants to enable a robust factor structure, usually between 40 and 60 individuals. $^{16}$

\section{Ethical approval}

This research received ethical approval from the ethics committee at the host institution (SoMREC/13/062). Informed written consent was gained from all participants.

\section{Procedure}

Data collection took place between April and June 2014. Each participant completed their Q sort individually, in 
Table 1 The gender equality interventions framework: categorisation of example interventions

\begin{tabular}{lcc} 
Intervention & $\begin{array}{l}\text { Intervention } \\
\text { target }\end{array}$ & $\begin{array}{l}\text { Intervention } \\
\text { level }\end{array}$ \\
\hline $\begin{array}{l}\text { Train all staff with management or recruitment roles in equality and diversity awareness and } \\
\text { unconscious bias }\end{array}$ & Good practice & Cultural \\
$\begin{array}{l}\text { Provide guidance for line managers about how to actively support staff taking a career } \\
\text { break so that their career is not disadvantaged on their return }\end{array}$ & Good practice & Organisational \\
$\begin{array}{l}\text { Support contributions to childcare or other carer costs for attending conferences via staff } \\
\text { development funding }\end{array}$ & Good practice & Individual \\
$\begin{array}{l}\text { Ensure all school websites have images that represent women carrying out a range of roles } \\
\text { including teaching and research at senior levels }\end{array}$ & Positive action & Cultural \\
$\begin{array}{l}\text { Design and implement a role review procedure for female academics during periods of } \\
\text { family commitment or part-time work so their academic output does not suffer }\end{array}$ & Positive action & Organisational \\
$\begin{array}{l}\text { Identify and recommend female staff to join grant review and journal editorial boards; } \\
\text { women are under-represented on these, yet they provide networking opportunities and } \\
\text { career benefits }\end{array}$ & Positive action & Individual \\
\hline
\end{tabular}

a one-to-one or a small group setting. Data collection was carried out by a researcher not employed within the School of Medicine. The interventions were presented to participants on a set of numbered cards, shuffled prior to administration. Verbal instructions about how to complete the $\mathrm{Q}$ sorting were given:

'Please read each card in turn. For each intervention, please consider how important you think it is for promoting gender equality in the School of Medicine'.

In a series of steps, participants ranked the interventions according to their priority (most important(1) to least important(9)) on to a grid in the form of a quasinormal distribution (see figure 1). Participants were asked to provide written statements about the reasons for their choices at both extremes of the grid, and this information was used to inform interpretation.

\section{Analysis}

Principal components analysis

Principal components analysis (PCA) with varimax rotation was used to identify relationships between individual $\mathrm{Q}$ sorts. The $\mathrm{Q}$ sort data were managed and analysed using dedicated software package PQMethod V.2.1. ${ }^{23}$ Each principal component (from now on referred to as a factor) represents a highly intercorrelated cluster of $Q$ sorts, that is, a set of items sorted in a statistically similar way that reflects a distinct point of view on action to reduce gender inequality in the participant's workplace. During the varimax rotation, established strategies were employed to identify the maximum number of interpretable and distinct viewpoints to take forward for interpretation. ${ }^{16}$ A scree test was applied to factors with an eigenvalue greater than 1 (Kaiser-Guttman criterion) with at least two significantly loading $Q$ sorts. The eigenvalues of these factors were plotted on a simple line graph: factors falling around the point the line changes slope and before the point where the line levels off were considered for rotation.
After the optimum number of factors had been selected, a weighted averaging formula was applied to exemplar $Q$ sorts to create a composite 'idealised' $Q$ sort to represent each factor (see figure 1). Exemplar $Q$ sorts are those that load significantly at $\mathrm{p}<0.01$ on one factor only and therefore best exemplify the viewpoint represented by the factor.

The interpretation of the unique configuration of statements for each factor requires a considered synthesis of the quantitative and qualitative data collected during the process. The information produced by PQMethod is used to inform the first level of interpretation: highest and lowest scores assigned to particular statements are considered first, as are statements statistically distinguishing for that factor at $\mathrm{p}<0.01$. Subsequently, a deeper level of interpretation takes place, whereby the whole $Q$ sort is considered holistically along with qualitative information provided by the participants. The output of the interpretation phase is a narrative account, or 'best possible theoretical explanation' of the factor. ${ }^{16}$ Initial $\mathrm{Q}$ factor analysis was conducted by the lead author, followed by iterations of different factor solutions, each discussed with coauthors to maintain transparency of the interpretation process and keep interpretation close to the data.

\section{Latent class analysis}

Latent class analysis (LCA), a statistical modelling tool widely used for market segmentation, was used to identify whether any discernible pattern in statement placement was associated with participant characteristics, particularly gender or academic role. This was implemented by use of the poLCA library within the R statistical software; mathematical details are provided elsewhere. ${ }^{24}$

\section{RESULTS}

The first aim of the study was to identify the range of viewpoints held by academic and research staff on how to address 


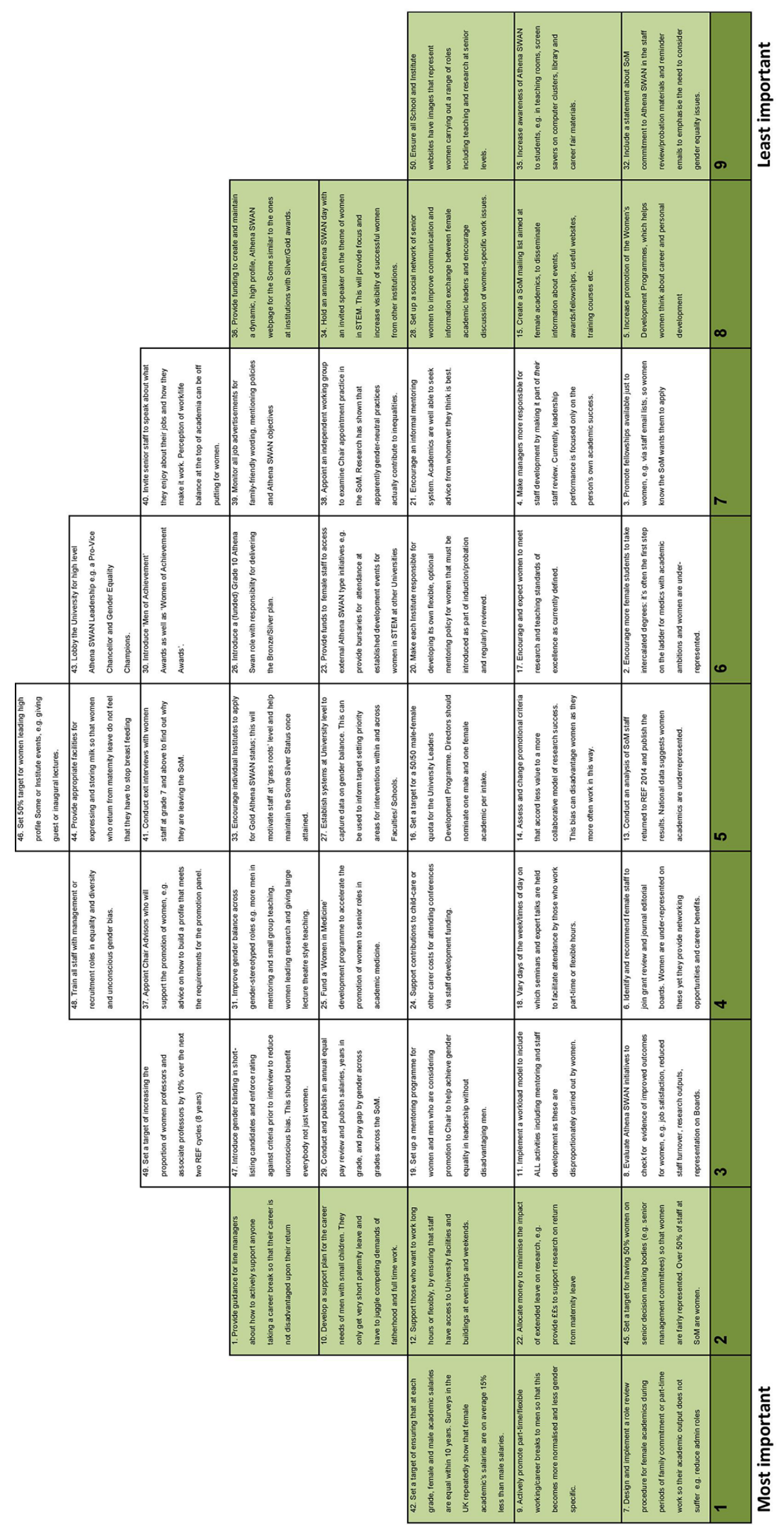

Figure 1 Factor 1 reconstructed as an idealised Q sort. 
Table 2 Summary of participant characteristics by gender $(n=55)$

\begin{tabular}{|c|c|c|c|}
\hline Characteristics & Total & Female & Male \\
\hline \multicolumn{4}{|l|}{$\mathrm{Age}^{*}$} \\
\hline Under 40 & $13(24 \%)$ & $8(62 \%)$ & $5(38 \%)$ \\
\hline $40-49$ & $22(40 \%)$ & $13(59 \%)$ & $9(41 \%)$ \\
\hline 50 plus & $18(33 \%)$ & $9(50 \%)$ & $9(50 \%)$ \\
\hline \multicolumn{4}{|l|}{ Ethnicity } \\
\hline White or British white & $51(93 \%)$ & $29(57 \%)$ & $22(43 \%)$ \\
\hline Other & $4(7 \%)$ & $2(50 \%)$ & $2(50 \%)$ \\
\hline \multicolumn{4}{|l|}{ Caring responsibilities* } \\
\hline No & $26(47 \%)$ & $14(54 \%)$ & $12(46 \%)$ \\
\hline Yes & $28(51 \%)$ & $16(57 \%)$ & $12(43 \%)$ \\
\hline \multicolumn{4}{|l|}{ Pay grade* } \\
\hline $\begin{array}{l}\text { Research assistant/ } \\
\text { fellow }\end{array}$ & $11(20 \%)$ & $6(55 \%)$ & $5(54 \%)$ \\
\hline $\begin{array}{l}\text { Senior research } \\
\text { fellow/assistant } \\
\text { professor }\end{array}$ & $10(18 \%)$ & $6(60 \%)$ & $4(40 \%)$ \\
\hline Associate professor & $15(27 \%)$ & $9(60 \%)$ & $6(40 \%)$ \\
\hline Professor & $18(33 \%)$ & $9(50 \%)$ & $9(50 \%)$ \\
\hline \multicolumn{4}{|l|}{ Full time or part-time* } \\
\hline Full time & $51(93 \%)$ & $27(53 \%)$ & $24(47 \%)$ \\
\hline Part-time & $3(5 \%)$ & $3(100 \%)$ & $0(0 \%)$ \\
\hline \multicolumn{4}{|l|}{ Employed by school* } \\
\hline Less than 10years & $24(44 \%)$ & $13(54 \%)$ & $11(46 \%)$ \\
\hline 10 or more years & $26(47 \%)$ & $15(58 \%)$ & $11(42 \%)$ \\
\hline \multicolumn{4}{|l|}{$\begin{array}{l}\text { Line management } \\
\text { responsibilities* }\end{array}$} \\
\hline No & $11(20 \%)$ & $5(45 \%)$ & $6(55 \%)$ \\
\hline Yes & $43(78 \%)$ & $25(58 \%)$ & $18(42 \%)$ \\
\hline \multicolumn{4}{|l|}{ Clinical responsibilities* } \\
\hline No & $42(76 \%)$ & $26(62 \%)$ & $16(38 \%)$ \\
\hline Yes & $12(22 \%)$ & $4(33 \%)$ & $8(67 \%)$ \\
\hline
\end{tabular}

*Where total does not equal $100 \%$, this indicates missing data.

gender inequality. A six-factor solution produced the best fit for the data in terms of providing the maximum number of distinct interpretable viewpoints. Each factor had at least three exemplar $Q$ sorts loading highly and significantly at $\mathrm{p}<0.01$ on that factor only, considered sufficient for further interpretation. ${ }^{19}$ These six factors together represented $51 \%$ of the total explained variance. The following factor interpretations are illustrated using anonymised written comments made by participants in relation to the placing of specific items. After each comment the participant number and the number of the $Q$ item referenced in the comment are given.

Factor 1: prioritise interventions to support research careers of women with childcare commitments

The $Q$ sorts of nine participants exemplified factor 1 (six women, three men). Ages ranged from 30 to 54 years.
Seven worked at assistant professor level or lower, three worked part-time, and six had caring responsibilities. All but one had line management responsibilities, and only one had clinical responsibilities.

In this viewpoint, family responsibilities have the most significant impact on a woman's career development. High priority interventions are therefore ones that address this.

"Family responsibilities fall disproportionately on women. Reducing the inevitable stress of dealing with family life and the conflicting requirements of work/family can only mean less stressed, more organised and thoughtful employees." (p19:7)

Interventions of high priority include a mix of best practice and positive action: clearer endorsement of flexible working patterns for all parents, action to reduce the gendered pay gap, and financial and administrative initiatives to support research after maternity leave or a career break. Positive action to increase numbers of women in senior decision-making roles is seen as a priority to improve representation of the issues that affect other women.

Lowest priority interventions are those aimed at culture change via raising the profile of women, for example the promotion of female role models via an Athena SWAN website. Interventions aimed purely at the individual level only (women-only social media networks) are viewed to have little material impact on the working environment and are essentially 'window dressing' activities (p54:35), distracting resources away from more important activities:

"Staff with family commitments are already under time pressure to be successful... I would not prioritise my time at work to look at websites/emails/social media." (p32:15)

\section{Factor 2: prioritise positive action to get more women into leadership}

The $Q$ sorts of three participants exemplified factor 2 (two men, one woman). Ages ranged from 40 to 61 years. All worked full time, and one had caring responsibilities. Two were full professors and one was an assistant professor. All line-managed staff and two had clinical responsibilities.

This view prioritises high-level interventions to increase the number of senior women in positions of influence and leadership. Setting targets, for example in terms of the number of women at chair level, "are essential otherwise there is no way to measure impact" (p9:49). High-priority interventions are those that encourage women to achieve excellence as currently defined ("we shouldn't lower the standards for women," p3:17) but focus on accelerating change. Supporting those women who want to achieve seniority is a priority, for example appointing advisors to women aiming for promotion. There is a need to understand why eligible women are less likely than men to apply for promotion at senior level. 
"We must know why women drop out of academia... this knowledge can be used to inform policy to enhance/improve promotion of women to Chairs." (p9:41)

Interventions aimed specifically at supporting women with young children are considered to represent a stereotypical view of gender inequality. As they will not activate high-level change, they were ranked as lowest priority. For similar reasons, activities aimed at women on an individual level, such as personal development training and women-only events, are low priority.

\section{Factor 3: prioritise the career development of all women, not just those aiming for the top}

The Q sorts of six participants exemplified factor 3 (four men, two women). Ages ranged from 40 to 61 years. Three had caring responsibilities. One participant did not provide further personal details, but of the remaining five all worked full time, four worked at associate professor or full professor grade, three had line management responsibilities, and five had clinical responsibilities.

In this view, and in contrast to factor 2 , the equality agenda places too much emphasis on supporting women aiming for leadership. Interventions should be a combination of positive action to support women's careers and good practice to develop all staff. It is essential to change organisational systems and practices that maintain gender inequality; otherwise all other interventions aimed at the individual level will be inconsequential. High-priority interventions are those that benefit all women, for example formal mentoring arrangements, access to flexible working, reviewing current promotional criteria that value 'male' over 'female' working styles, and traditional linear career trajectories. A priority is financial investment such as funding to support research after maternity leave. In contrast to factors 1 and 2, it is considered important to raise the profile of women as part of changing organisational culture, for example by funding a high-profile website.

"Exceptional women have always reached the top [but] we need positive role models to show women academics that senior posts are for women like them." (p76:40)

Lowest priority interventions are measures just for women aiming for leadership, for example senior women's networks. Setting targets, for example in terms of the number of women at chair level, was also low priority partly because targets are seen as tokenistic but also potentially disadvantageous to the institution in light of initiatives like Athena SWAN:

"What would happen if the target was not reached?" (p37:49)

Factor 4: prioritise leadership responsibility for driving change The $Q$ sorts of seven participants exemplified factor 4 (six women, one man). Ages ranged from 45 to 60 years. All worked full time, and four had caring responsibilities. Four were associate professors and three were full professors. All had line management responsibilities and four had clinical responsibilities.

According to this view, significant steps such as eliminating the gender pay gap will only happen if those in leadership roles take responsibility for driving change. High-priority interventions are therefore those that represent positive action at an organisational level.

"High level, central [University] support would send a meaningful signal - I like the idea of [gender equality] “champions.”' (p4:43)

As in factor 2, increasing the promotion of women to chair is a priority and must be accelerated. In contrast to factor 2 and in line with factor 3 , current standards of excellence are seen as gendered and act to maintain inequality because they disadvantage working styles more frequently found in women than men.

"Plenty of research suggests women are more likely to work collaboratively and include citizenship and teaching. [Make] sure these are rewarded in promotions criteria." (p69:14)

Lowest priority interventions are those to support men with families and those that impact a minority of women, such as facilities for storing breast milk at work.

\section{Factor 5: prioritise interventions that recognise merit irrespective of gender}

The $Q$ sorts of five participants exemplified factor 5 (four men, one woman). Ages ranged from 27 to 62 years. All exemplars worked full time and one had caring responsibilities; four were associate professor or professor grade, four had clinical responsibilities, and two had line management responsibilities.

According to this viewpoint merit should be judged irrespective of gender: positive action discriminates against men and is patronising to women.

"Any incentive that is based on gender alone unjustly discriminates against men. This could lead to talented and hardworking male academics being unfairly bypassed for promotion in favour of women." (p47:25)

Promotion, selection for leadership training or invitation to join a committee should be entirely down to merit. The best way to support the career development of women is to prioritise interventions that benefit all staff, for example gender blinding when shortlisting for interviews and training managers in equality and diversity issues. Staff should feel free to identify who they want and if they want - to seek mentoring from rather than having formal schemes for women. Senior staff talking to colleagues about how they balance work and home life may help women identify whether or not they want to seek promotion.

Lowest priority interventions are those associated with setting 'artificial' equality targets; these are positive discrimination and may not result in improved outcomes for women. Resources should not be put into initiatives 
aiming to benefit women only, and top-down directives are not the best ways to enact culture change.

"Setting targets is unlikely to promote equality. Many [women] may feel they have only been chosen because of the target and not because they deserve to be there." (p15:46)

\section{Factor 6: prioritise good practice in line management and} career development

The $Q$ sorts of five participants (three men, two women) exemplified factor 6 . Ages ranged from 47 to 53 years. All worked full time, and one had caring responsibilities. Four were associate professor or professor pay grade. Three had line management responsibilities and four had clinical responsibilities.

In this view achieving gender equality can be best achieved by improving existing practice such as ensuring compliance with annual staff reviews rather than new initiatives. This approach benefits all staff not just women. For example, managers need guidance on how to help people maintain a research trajectory following a career break.

"This will benefit women and men. Poor management and leadership is a leading cause of dissatisfaction. Women are often reluctant to bring up or challenge problems caused by this, or to insist their manager help with their career development." (25:4)

It is a priority to have someone at a senior level in each department responsible for implementing existing good practice. Low-priority interventions include those that change current practice, for example gender blinding at interviews or having core meeting times to support those who work part-time or flexibly.
"I don't think this would have much impact. More staff would find a regular slot much easier." (p35:18)

PCA did not find any participant characteristics obviously aligned with particular viewpoints, although factor 1 included all the participants who worked part-time and those participants were all women.

\section{LCA by gender}

The second objective of the study was to identify attitudinal barriers to implementing these interventions. LCA analysis was employed to identify any significant latent relationships between participant characteristics and the placing of specific statements to help identify attitude differences by group. To avoid overfitting only the most discriminating $Q$ items were retained in the LCA model. The statements discriminating most by gender were items 36, 45, 46 and 49 (see table 3); there were no interpretable results using other participant characteristics. For each participant values were assigned to each of these items using their placement on the $Q$ sorting grid: low, medium or high priority.

A satisfactory fit of the multigroup model was achieved using two classes regressed on gender. The probability of a participant being in class 1 as opposed to class 2 was provided by a logistic regression. The OR for female gender being in class 2 was 3.56, with a $95 \%$ CI 0.94 to 13.46 , indicating that female participants were more likely to place the discriminating items in the pattern seen for class 2 than for class 1 , and vice versa for men. The class frequencies are given in table 3. Overall, women were more likely than men to give high priority to interventions related to setting 'hard' equality targets. Women were less likely to give

Table 3 Latent class analysis: table of class frequencies

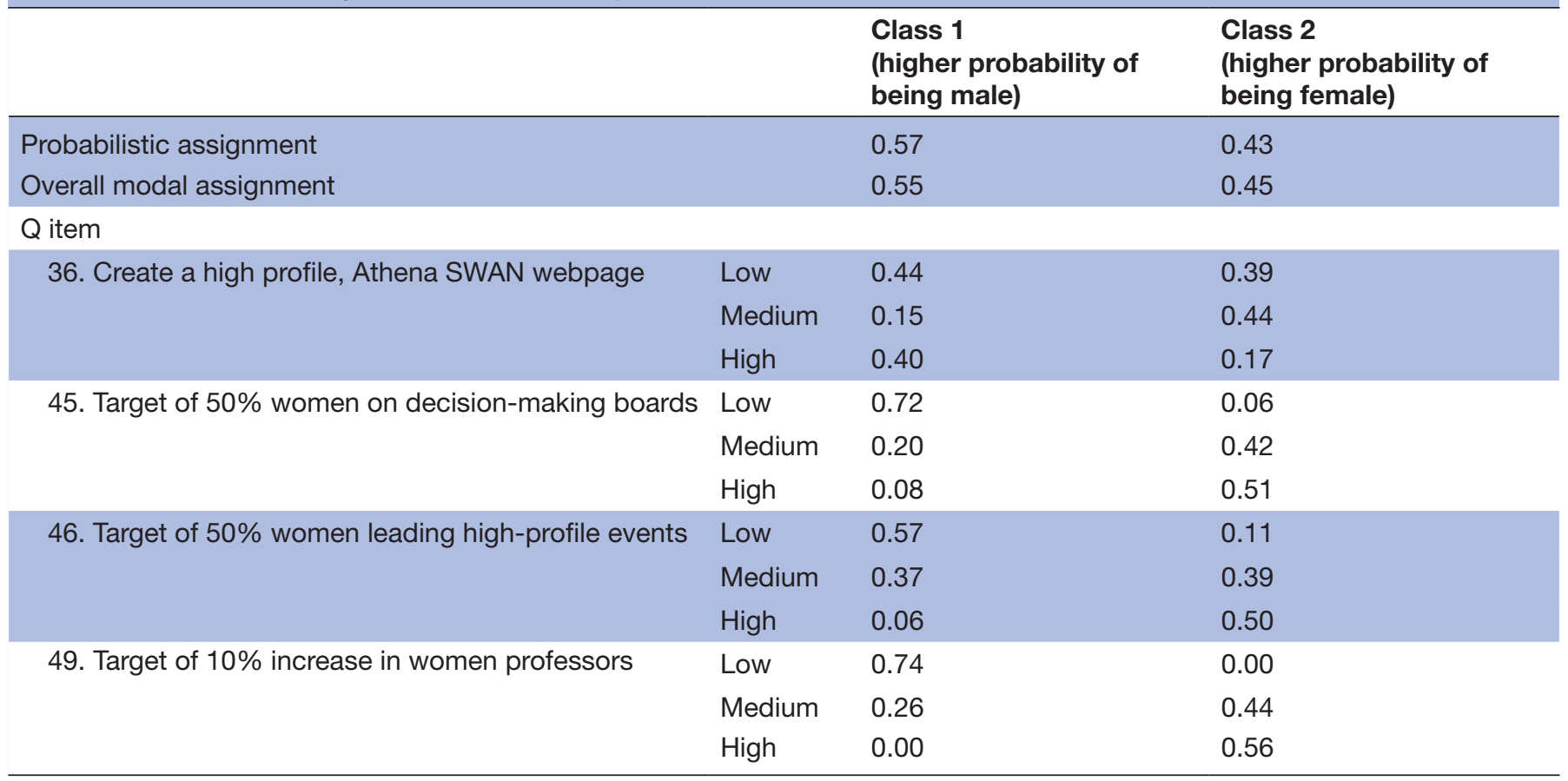


high priority to the development of an 'Athena SWAN' website when compared with men.

\section{DISCUSSION}

This study had two objectives: (1) identify different staff viewpoints on the prioritisation of a range of gender equality interventions in the workplace and (2) identify barriers and facilitators to implementing these interventions. Six significantly different viewpoints were identified demonstrating the complexity of the debate on addressing gender equality in the workplace. A key finding of our research was the strong divergence in views as to whether good practice or positive action was the most appropriate strategy for achieving gender equality. While all viewpoints prioritised some positive action interventions (interventions to support women) as well as good practice initiatives (interventions to support all staff), the balance of these approaches and the strength of the favoured positive action initiatives varied greatly. No viewpoint identified via the $Q$ factor analysis was clearly associated with any participant characteristic, although LCA suggested that men may be less likely than women to be in favour of setting 'hard' positive action targets.

Factor 5 represents the strongest rejection of positive action, seeing it as a form of social engineering that will undermine the meritocratic principles of academic institutions. In this view, positive action is considered a means to advance less academically excellent women over academically excellent men. Women deserve fair treatment but not favoured access to career development initiatives. Resentment about perceived positive discrimination embedded within Athena SWAN has been recorded elsewhere. ${ }^{25}$ Factor 6 also favoured good practice with a focus on improving existing management practice to ensure women and men are treated equally. The favouring of good practice interventions supports the view of universities as meritocracies. However, experimental research suggests that managers who see themselves as affiliated with an organisation espousing meritocratic values are no less likely to manifest a favourable bias towards men in terms of monetary rewards at least than those who do not see their organisation as explicitly meritocratic. ${ }^{26}$ It has been argued elsewhere that 'excellence', as the new keyword in higher education, ${ }^{27}$ is not a gender-neutral marker of merit. ${ }^{28}{ }^{29} \mathrm{In}$ this study, factor 4 agreed that assessment of excellence was gendered; for example, promotions criteria were seen to be biased towards individual 'masculine' leadership styles over collaborative 'feminine' styles.

The most common reason given for women not progressing into senior posts is the negative impact on career progression caused by the bearing and raising of children - the so-called 'motherhood penalty'. ${ }^{30}$ Factor 1 endorsed this as the main obstacle to career progression, and prioritised support for flexible working and other initiatives to meet the needs of staff with young children. In contrast, factor 4 viewed the focus on women with children as a distraction from the main issue of a gender power imbalance. Initiatives to support women with young families are less controversial in the workplace than quotas or equality targets; most universities support flexible working and other 'family friendly' initiatives. It has been argued, however, that a focus on these policies can in fact strengthen the expectation that women undertake a disproportionate amount of caring work in families. ${ }^{31}$ Family-friendly policies do not help challenge attitudes, which women may also internalise, that mothers are less competent academics or medics, are less committed to their careers and are less suited to leadership positions than men. $^{32}$

\section{Implications for gender equality work in medical schools}

As our school's Athena SWAN work has developed, the initiatives have been evaluated using our framework to ensure that as many different priorities as possible are addressed. For example, to address factor 1 concerns about the impact of childbearing on career, the school has implemented a popular bursary scheme to support the academic trajectory of those taking a period of maternity or adoption leave. The development of the gender equality intervention framework has, however, helped us avoid too narrow a focus on interventions aimed at 'fixing' individuals. ${ }^{21}$ A positive but intangible benefit of conducting the research is that it was an intervention in itself, raising the profile of gender equality and the possibility for change within the school. We have also set targets to increase the number of female clinical professors and reduce the gender pay gap in our academic staff to address priorities of those in factors 2 and 4 . The finding that men, who still comprise the majority in terms of holding high-level decision-making power in medical schools, are less supportive of positive action programmes may indicate an attitudinal barrier to achieving these targets that needs to be addressed.

A limitation of using the framework is that it is descriptive and does not take into account the existing culture of an organisation and the fact that some interventions are more easily implemented than others. Some interventions also have a strong immediate appeal despite there being limited evidence of their effectiveness. Our Athena SWAN plan, like many others, includes unconscious bias training and mentoring schemes, although neither of these interventions featured strongly in our findings. Finally, while the data were collected by a researcher not employed within the School of Medicine, the $\mathrm{Q}$ analysis and interpretation were carried out in collaboration with coauthors who are academics employed within the school. The interpretation of the findings was therefore likely to have been informed by cultural context of the school within which four of the coauthors were situated. Other possible interpretations could be made by those external to this context. 


\section{CONCLUSIONS}

We believe the findings of the study and the approach taken have significant utility for those involved in gender equality work in other medical schools within and outside of the UK, even though we recognise that $Q$ methodology does not identify the prevalence of particular views nor deal with the reality that certain viewpoints (or the viewpoints of certain individuals) may hold more influence than others. Nevertheless, the illumination of areas of agreement and discord via $Q$ methodology makes a useful contribution to decision making in areas where contentious action may be needed to overcome attitudinal barriers to positive action. ${ }^{33}$ Finally, a note of caution: tying the Athena SWAN Silver status to research funding has not yet demonstrated a significant overall impact on the careers of women in UK medical schools. ${ }^{14}$ A continued evaluation of the outcomes of these and similar initiatives is essential if their value and status are to be upheld. ${ }^{25}$

Contributors $\mathrm{LDB}, \mathrm{AOH}$ and VW conceived and designed the study. PB and LDB made substantial contributions to the acquisition of the data. $\mathrm{LDB}, \mathrm{AOH}, \mathrm{VW}$ and PB made substantial contributions to the analysis and interpretation of the $Q$ methodology data. RMW designed and conducted the latent class analysis. LDB and RMW conducted the latent class analysis interpretation. LDB drafted the manuscript and integrated critical feedback and important content from all of the other authors. All of the authors read and approved the final version of the manuscript.

Funding This research received no specific grant from any funding agency in the public, commercial or not-for-profit sectors. The contributors were funded by the School of Medicine, University of Leeds.

Disclaimer All authors have completed the ICMJE uniform disclosure form at www.icmje.org/coi_disclosure.pdf and declare no support from any organisation for the submitted work. LDB, AOH, VW and RMW have received NIHR funding in the previous 3 years. Accreditation by the Athena SWAN programme is a prerequisite for certain NIHR funding, although not that received by LDB, AOH, VW or RMW. There are no other relationships or activities that could appear to have influenced the submitted work.

Competing interests Grant funding for research but no other competing interest. Patient consent Obtained.

Ethics approval School of Medicine Research Ethics Committee, University of Leeds.

Provenance and peer review Not commissioned; externally peer reviewed.

Data sharing statement There are no unpublished data from the study.

Open Access This is an Open Access article distributed in accordance with the Creative Commons Attribution Non Commercial (CC BY-NC 4.0) license, which permits others to distribute, remix, adapt, build upon this work non-commercially, and license their derivative works on different terms, provided the original work is properly cited and the use is non-commercial. See: http://creativecommons.org/ licenses/by-nc/4.0/

(C) Article author(s) (or their employer(s) unless otherwise stated in the text of the article) 2017. All rights reserved. No commercial use is permitted unless otherwise expressly granted.

\section{REFERENCES}

1. Van den Brink M. Scouting for talent: appointment practices of women professors in academic medicine. Soc Sci Med 2011;72:2033-40.

2. Yasukawa K. Gender inequality in academic medicine in Japan. Med Teach 2013;35:700.

3. Medical Schools Council. A survey of staffing levels of medical clinical academics in UK Medical Schools as at 31 July 2015. London: Medical Schools Council, 2016.
4. Pell AN. Fixing the leaky pipeline: women scientists in academia. $J$ Anim Sci 1996;74:2843-8.

5. Magnusson $\mathrm{C}$. The gender wage gap in highly prestigious occupations: a case study of Swedish medical doctors. Work Employment \& Society 2016;30:40-58.

6. Cochran A, Elder WB, Crandall M, et al. Barriers to advancement in academic surgery: views of senior residents and early career faculty. Am J Surg 2013;206:661-6.

7. Shollen SL, Bland CJ, Finstad DA, et al. Organizational climate and family life: how these factors affect the status of women faculty at one medical school. Acad Med 2009;84:87-94.

8. Nomura K, Gohchi K. Impact of gender-based career obstacles on the working status of women physicians in Japan. Soc Sci Med 2012;75:1612-6.

9. Pololi LH, Civian JT, Brennan RT, et al. Experiencing the culture of academic medicine: gender matters, a national study. J Gen Intern Med 2013;28:201-7.

10. Zhuge Y, Kaufman J, Simeone DM, et al. Is there still a glass ceiling for women in academic surgery? Ann Surg 2011; 253:637-43.

11. Blackmore J. Wasting talent? Gender and the problematics of academic disenchantment and disengagement with leadership. Higher Education Research \& Development 2014;33:86-99.

12. Ovseiko PV, Edmunds LD, Pololi LH, et al. Markers of achievement for assessing and monitoring gender equity in translational research organisations: a rationale and study protocol. BMJ Open 2016;6:e009022.

13. Equality Challenge Unit. ECU's Athena SWAN Charter Awards Handbook 2015.

14. Gregory-Smith I. The impact of Athena SWAN in UK medical schools. the Sheffield Economic Research Paper Series (SERPS). Department of Economics, University of Sheffield, 2015.

15. DeCourville $\mathrm{NH}$, Hafer CL. Attitudes towards affirmative action programs: a Q methodological study. Operant Subjectivity 2001;24:183-200.

16. Watts S, Stenner P. Doing Q Methodological Research. London: SAGE, 2012.

17. Brown SR. A primer on $Q$ methodology. Operant Subjectivity 1993;16:91-138.

18. Stainton Rogers R. Q Methodology. In: Smith JA, Van Langenhove L, eds. Rethinking methods in psychology. London: Sage, 1995:178-92.

19. Stenner P, Watts S, Worrell M. Q Methodology. In: Willig C, StaintonRogers W, eds. The SAGE Handbook of Qualitative Research in Psychology. London: SAGE, 2008:215-39.

20. Rees T. Mainstreaming gender equality in science in the European Union: the 'ETAN Report' Gend Educ 2001;13:243-60.

21. Ely RJ, Meyerson DE. Theories of gender in organizations: a new approach to organizational analysis and change. Research in Organizational Behavior 2000;22:103-51.

22. Ferlie EB, Shortell SM. Improving the quality of health care in the United Kingdom and the United States: a framework for change. Milbank Q 2001;79:281-315.

23. Schmolck P, Atkinson J. PQMETHOD (Version 2.11). Munich: University of the Federal Armed Force, 2003. http://www.rz.unibwmuenchen.de/ p41bsmk/qmethod/

24. Linzer DA, Lewis JB. poLCA : an $R$ package for polytomous variable latent class analysis. J Stat Softw 2011;42:1-29.

25. Ovseiko PV, Chapple A, Edmunds LD, et al. Advancing gender equality through the athena SWAN charter for women in science: an exploratory study of women's and men's perceptions. Health Res Policy Syst 2017;15:12.

26. Castilla EJ, Benard S. The Paradox of Meritocracy in Organizations. Adm Sci Q 2010;55:543-676.

27. Allan KL. Excellence: a new keyword for education? Crit $Q$ 2007:49:54-78.

28. van den Brink M, Benschop Y. Gender practices in the construction of academic excellence: sheep with five legs. Organization 2012;19:507-24.

29. Thornton M. The mirage of merit. Australian Feminist Studies 2013;28:127-43.

30. Correll Shelley J, Benard S, Paik I. Getting a Job: is there a Motherhood Penalty? Am J Sociol 2007;112:1297-339.

31. Caffrey L, Wyatt D, Fudge N, et al. Gender equity programmes in academic medicine: a realist evaluation approach to Athena SWAN processes. BMJ Open 2016;6:e012090.

32. Parkman $\mathrm{A}$. The imposter phenomenon in higher education: incidence and impact. J Higher Edu Theory and Practice 2016;16:51.

33. Baker R, Wildman J, Mason H, et al. Q-ing for health--a new approach to eliciting the public's views on health care resource allocation. Health Econ 2014;23:283-97. 